\title{
COMBINED CONGENITAL SUBAORTIC STENOSIS AND INFUNDIBULAR PULMONARY STENOSIS*
}

\author{
BY \\ HENRY N. NEUFELD, $\dagger$ PATRICK A. ONGLEY, AND JESSE E. EDWARDS \\ From the Sections of Padiatrics and Pathological Anatomy, Mayo Clinic and Mayo Foundation, \\ Rochester, Minnesota, U.S.A. \\ Received February 3, 1960
}

Coexistent congenital obstruction to both the right ventricular and left ventricular outflow tracts is rare. Only a few cases have been reported (Beard et al., 1957; Braunwald, 1959; Horlick and Merriman, 1957; Neufeld et al., 1960). Only two of about 800 specimens in the Mayo Clinic pathological collection of congenitally defective hearts represent this condition. It is the purpose of this communication to report these two cases.

\section{CASE REPORTS}

Case 1, a boy aged 1 month, was studied clinically and at necropsy. Pregnancy and delivery were uneventful. Cyanosis had been present from birth and was accentuated on exertion. Oxygen and digitalis were administered because of cardiac failure. Examination on admission to a hospital under care of the Mayo Clinic revealed a small, white boy not obviously cyanotic at rest. The peripheral pulses were normal. The liver extended $3 \mathrm{~cm}$. below the right costal margin and was not pulsating. The spleen was not palpable. The heart was generally enlarged and manifested a right ventricular type of impulse to palpation. A systolic thrill was palpable along the left sternal border. The first heart sound was diminished in intensity at the apex and the second sound was inaudible at the pulmonary area. A grade 3 systolic stenotic murmur was heard, being loudest at the second left interspace at the sternal border, but being also well transmitted to the suprasternal notch, toward the back and over the left præcordium. The electrocardiogram showed right ventricular hypertrophy (Fig. 1). Radiological examination showed cardiac enlargement with normal or slightly diminished pulmonary vasculature (Fig. 2). The clinical diagnosis was pulmonary stenosis with intact ventricular septum, patent foramen ovale, and right-to-left shunt at the atrial level. Surgical intervention was planned, but the boy died suddenly after an acute attack of severe cyanosis.

Case 2 was that of a stillborn full-term male infant who was studied at necropsy.

\section{PATHOLOGY}

The hearts in the two cases were so similar in appearance that they may be described together (Fig. 3, 4, and 5). Each showed considerable generalized enlargement and hypertrophy, was estimated to weigh about four times the normal, and had an abnormally long shape.

The great vessels were normally related. The venous connections with the heart were normal.

The outflow portion of the ventricular septum was unusually thick and protruded into each of the outflow tracts, creating subpulmonic and subaortic stenosis. On the right side the crista supraventricularis was prominent and contributed to the stenosis, but the septum marginalis

\footnotetext{
* This investigation was supported in part by Research Grant No. 4014 from the National Heart Institute, U.S. Public Health Service.

† Cardiologist, Tel-Hashomer Government Hospital, Israel.
} 


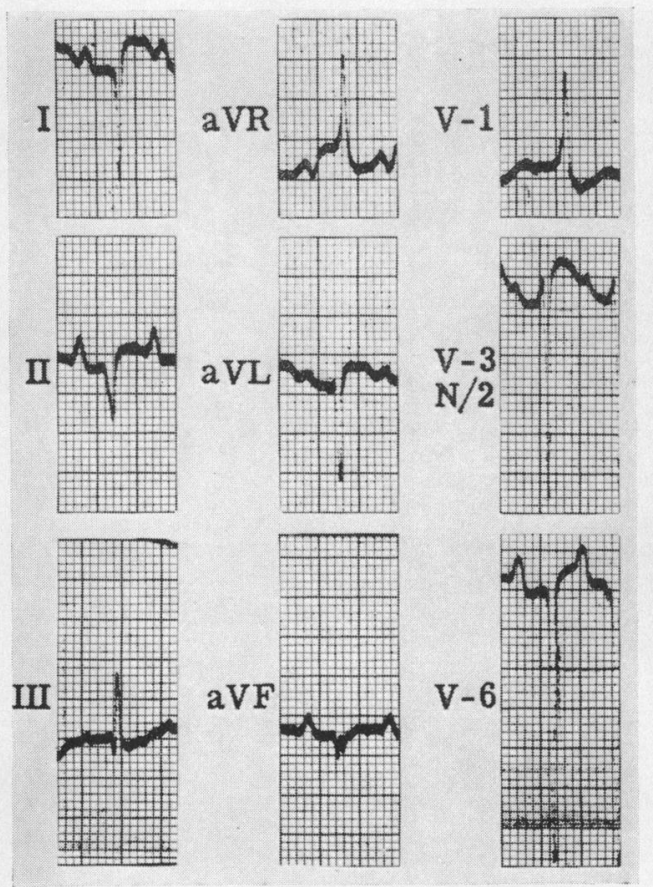

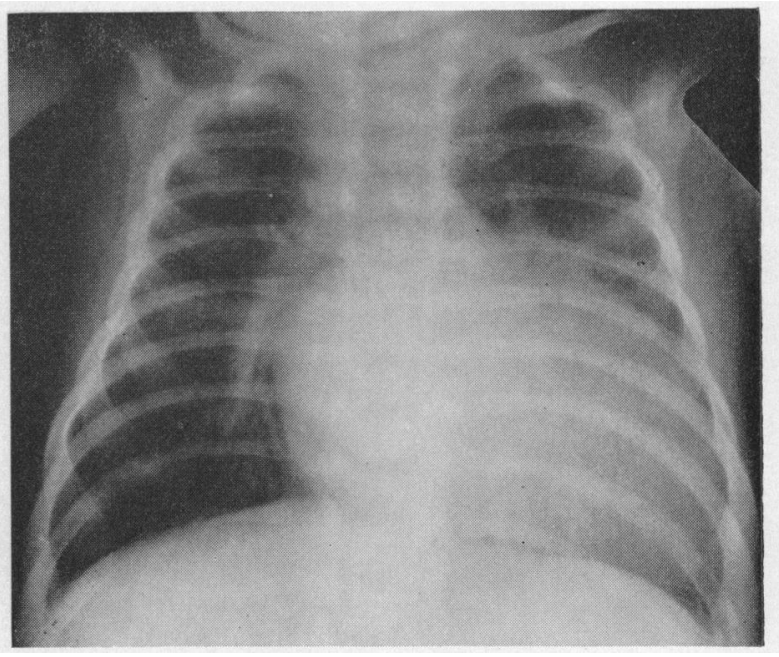

FIG. 2.- Roentgenogram, showing generalized cardiomegaly. Pulmonary vasculature is normal or only slightly diminished. Case 1.

FIG. 1.-Electrocardiogram, showing axis of -170 degrees. Right ventricular hypertrophy is shown by dominant $R$ waves in leads V1 and aVR and deep $\mathrm{S}$ waves in V6. Case 1.

branch of the crista on the ventricular septum was more prominent. On the left side the prominence of the ventricular septum was represented by a uniform convexity protruding into the outflow tract, the most prominent crest of which was centred about $1.5 \mathrm{~cm}$. below the aortic valve. The endocardium over the thickened portion of the ventricular septum, both in the right and in the left ventricle, was slightly thickened.

The pulmonary trunk and the aorta had normal anatomical relationships and were of normal size; the valve of each was equipped with three normal semilunar cusps.

The foramen ovale of each heart showed valve-competent patency. The atrio-ventricular valves were normal. No ventricular septal defect existed. The wall of each ventricle was hypertrophied. In the older infant (Case 1) the left ventricular wall was about $10 \mathrm{~mm}$. thick, while the right ventricular wall was from 5 to $8 \mathrm{~mm}$. thick. In the younger patient (Case 2) the left ventricular wall was $12 \mathrm{~mm}$. thick and the right ventricular wall $13 \mathrm{~mm}$. thick. The ductus arteriosus was widely patent in the stillborn patient, but was narrowly patent, measuring $2 \mathrm{~mm}$. in diameter in the older patient. The distribution of the coronary arteries was normal.

\section{Discussion}

With the present developments of cardiac surgery, the combined anomaly reported is potentially correctable, and successful surgical correction has been reported in one case (Beard et al., 1957).

It seems of great importance that a surgical plan for this condition provide for relief of both obstructions at the same operation. After correction of the infundibular pulmonic stenosis the pulmonary flow may increase, so that a greater volume of blood is delivered to the left ventricle.

If obstruction to the outflow from the left ventricle is not relieved, this ventricle may fail, causing 

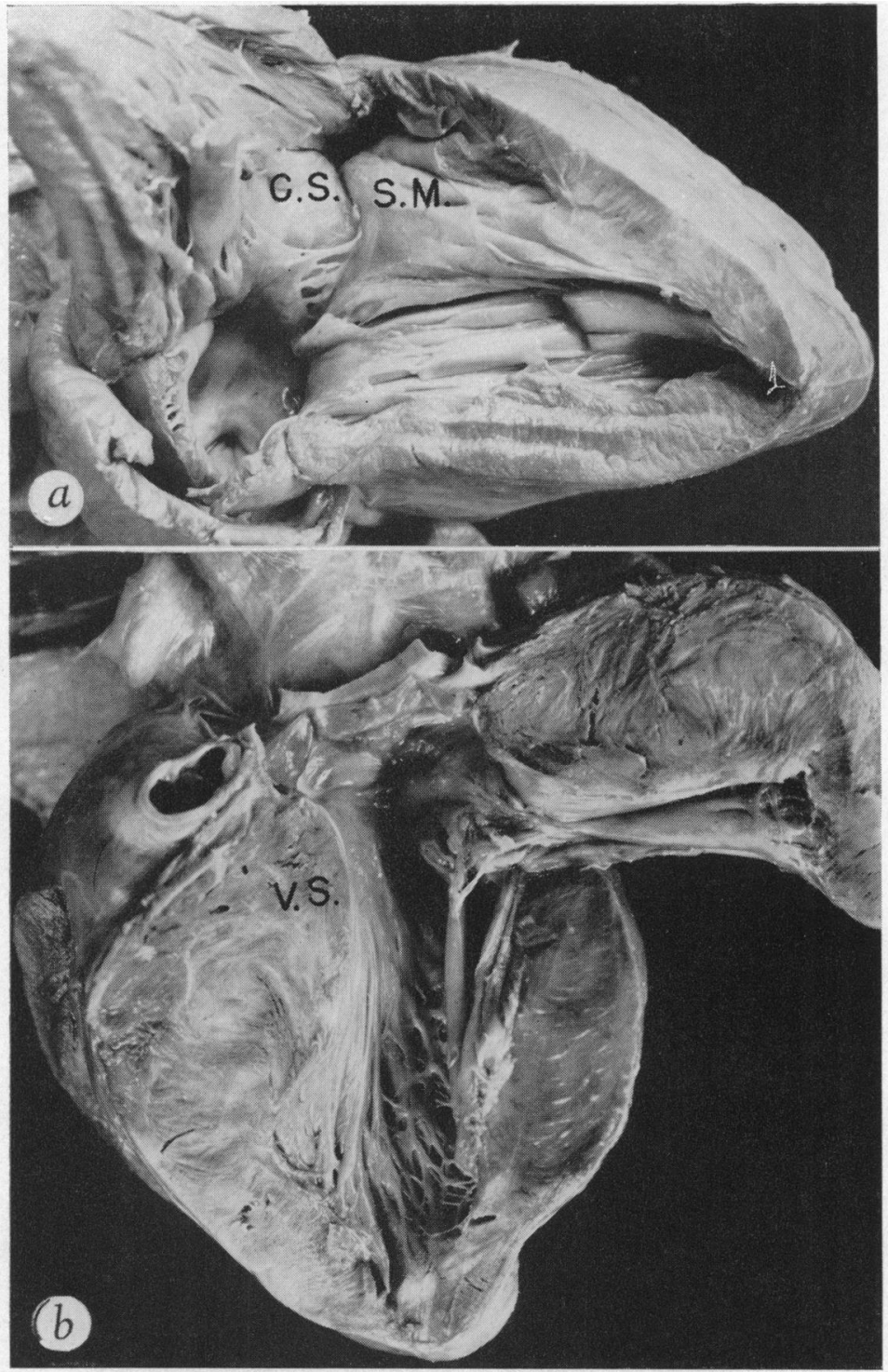

FIG. 3. Case 1.-(a) Right ventricle. In the infundibular region of the right ventricle the crista supraventricularis (C.S.) and the crista septomarginalis (S.M.) are greatly hypertrophied, creating much narrowing of the infundibular region of the right ventricle. The right ventricular wall is hypertrophied. The downward elongation of the ventricular chambers is also apparent. (b) Left ventricle and aortic valves. The ventricular septum (V.S.) is greatly hypertrophied in the region of the outflow tract of the left ventricle. The prominence protrudes into the outflow tract and creates subaortic stenosis. There is mild fibrous thickening of the endocardium over the stenotic zone. The aortic valve is normal. The left ventricular wall is hypertrophied in general, but not to the extreme degree displayed by the ventricular septum. 

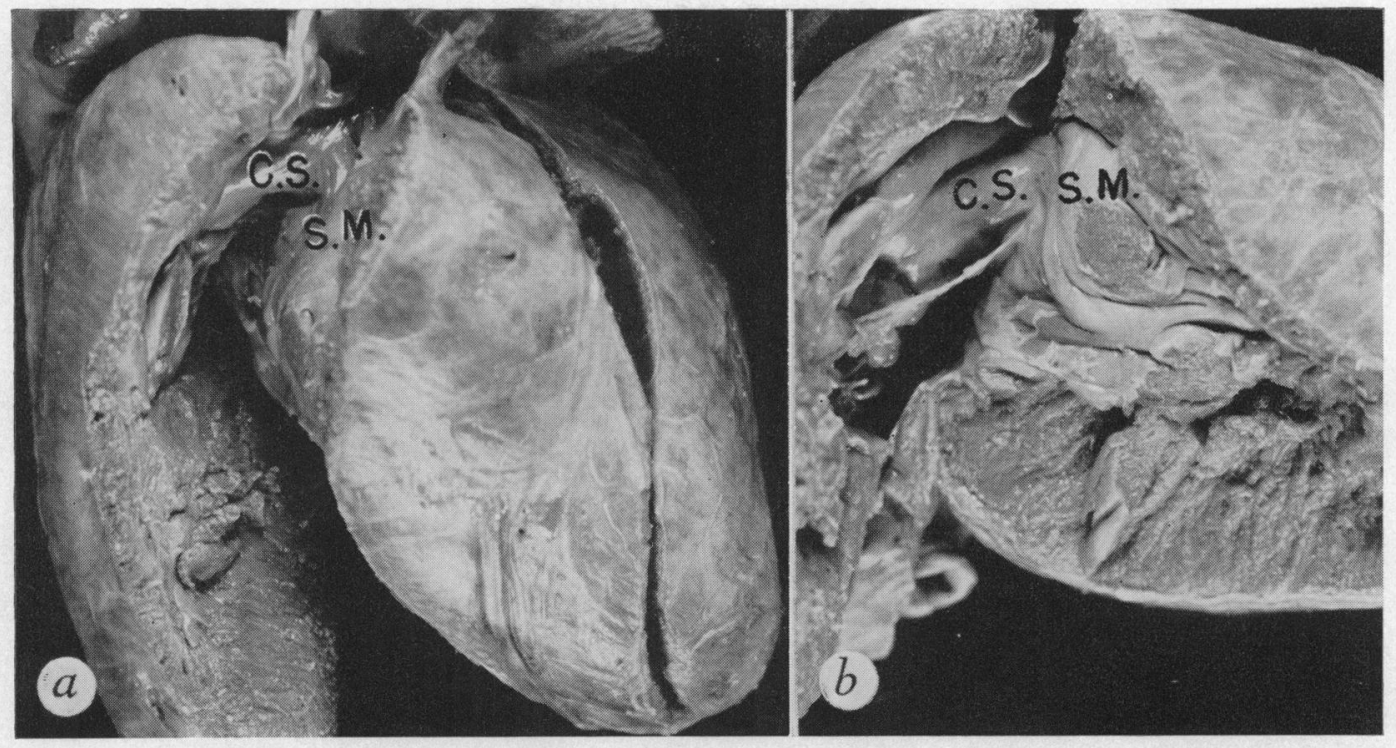

FIG. 4. Case 2.-(a) Outflow tract of right ventricle viewed from below. The crista supraventricularis (C.S.) and the crista septomarginalis (S.M.) are prominent. The two combined with hypertrophy of the ventricular wall create infundibular stenosis. (b) Outflow tract of the right ventricle viewed from the front, showing prominent protrusion of the ventricular septum into the outflow tract of the right ventricle.

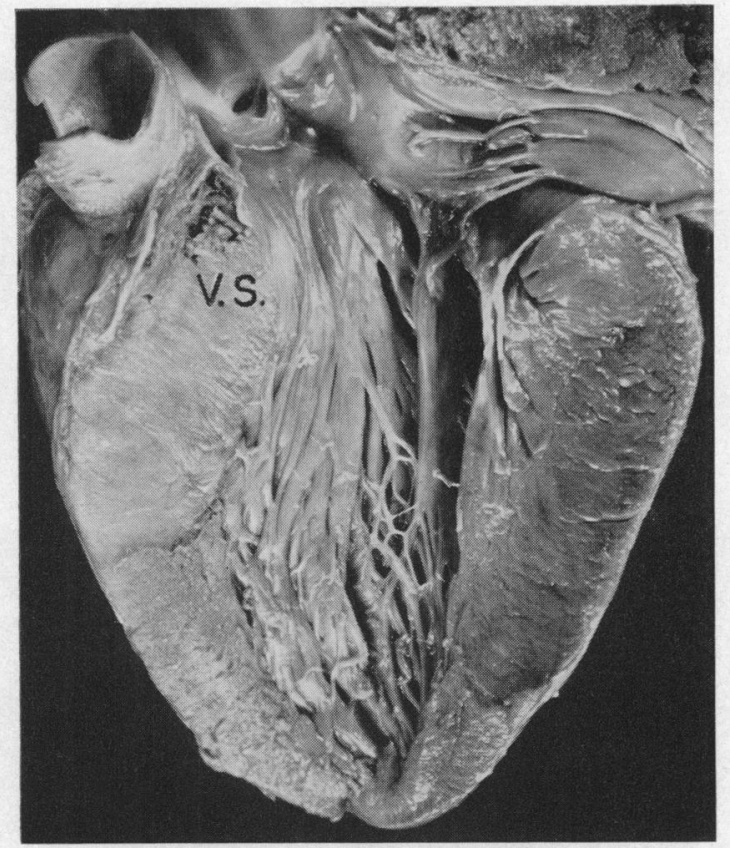

Fig. 5. Case 2.-Left ventricle. Prominence of the ventricular septum (V.S.) in the subaortic region has caused narrowing of the outflow tract of the left ventricle. The ventricle is hypertrophied generally. The aortic valve is normal. 
pulmonary œdema as in the cases of Sissman et al. (1959) and of Horlick and Merriman (1957).

As far as we are aware, in each reported instance and in our cases the clinical picture did not suggest obstruction to the outflow of both ventricles. In the case reported by Beard et al. the clinical evidence pointed only to left ventricular obstruction; obstruction to the right ventricular outflow tract was discovered at the time of cardiac catheterization. In the other cases the clinical picture suggested obstruction only to right ventricular outflow. In one of our cases the electrocardiogram showed signs only of right ventricular hypertrophy. In discussing the case of Sissman et al. (1959), Taussig suggested that the deep S waves over the right præcordium seen in that case were suggestive signs of additional obstruction to left ventricular outflow. Patterns similar to those in the case of Sissman et al. were observed in the case of Neufeld et al. (1960).

Another clinical aid in diagnosis might be the diminution or absence of the second sound in the aortic area, although the presence of a normal second aortic sound does not exclude concomitant aortic stenosis.

It is apparent from the limited material available that identification of combined ventricular obstruction by clinical means is difficult. Catheterization of the left side of the heart, left ventricular puncture simultaneously with catheterization of the right side of the heart, and cineangiocardiography may permit more exact clinical evaluation of this condition, but these studies are not routine and are carried out only when clinical evidence suggests lesions in both the right and left ventricular outflow tracts.

The anatomy in the three cases that have been reported was different from those in our cases. In the case of Sissman et al. (1959) there was pulmonary valvular and infundibular stenosis. The aortic valve was also stenotic, and beneath it a fibrous band ran from the base of the aorta to the mitral valve and caused subvalvular stenosis.

In Horlick and Merriman's (1957) case the three pulmonary cusps were thickened and fused, with narrowing of the orifice. The aortic valve was tricuspid, and the cusps were thickened and fused with a much narrowed valve orifice.

In the case of Beard et al. (1957), as described at the time of operation, a typical infundibular chamber measuring $3 \mathrm{~cm}$. in diameter was situated at the outflow tract of the right ventricle. The aortic cusps were normal, but about $1 \mathrm{~cm}$. beneath them there was a subvalvular fibrous membrane with an eccentrically placed small orifice.

\section{SUMMARY}

Two cases of combined congenital infundibular pulmonary stenosis and subaortic stenosis are reported and discussed. In one case, in which clinical examination was done, the findings of pulmonary stenosis obscured those of subaortic stenosis.

\section{REFERENCES}

Beard, E. F., Cooley, D. A., and Latson, J. R. (1957). Arch. intern. Med., 100, 647.

Braunwald, E. Quoted by Sissman, et al. (1959). Circulation, 19, 458.

Horlick, L., and Merriman, J. E. (1957). Amer. Heart J., 54, 615.

Neufeld, H. N., Hirsch, M., and Pauzner, J. (1960). Amer. J. Cardiol. (in press).

Sissman, N. J., Neill, C. A., Spencer, F. C., and Taussig, H. B. (1959). Circulation, 19, 458. 